\title{
Effect of haemodynamic changes during rapid atrial pacing on determination of sinus node recovery time
}

\author{
REINHARD GRIEBENOW, FRIEDHELM SABOROWSKI, ERHARD GODEHARDT , \\ VOLKER HOSSMANN, BERND ALFS \\ From the Department of Internal Medicine II and the ${ }^{\star}$ Department of Medical Statistics and Documentation, \\ University of Cologne, Cologne, Federal Republic of Germany
}

SUMMARY Arterial blood pressure was continuously monitored during rapid atrial pacing in 31 patients with different types of heart disease to determine sinus node recovery time and corrected sinus node recovery time. Pacing was initiated at 70 beats $/ \mathrm{min}$ and increased stepwise to 160 beats/min. One to one atrioventricular conduction was maintained throughout the one minute stimulation period. Blood pressure fell initially during at least one stimulation period in 21 of our patients and at pacing rates up to 130 beats/min in 18 . Once blood pressure had fallen during overdrive pacing maximal sinus node recovery time and maximal corrected sinus node recovery time could not be prolonged by increasing the pacing rate. Sinus node recovery time and corrected sinus node recovery time during the pacing induced fall in blood pressure were significantly shorter than those during stimulation runs with constant blood pressure. No pacing induced fall in blood pressure and no relation between changes in blood pressure and sinus node recovery time were evident in 10 of the 31 patients. Sinus node recovery time is therefore influenced by alterations in autonomic tone due to pacing induced haemodynamic changes.

One diagnostic method for evaluating sinus node function is the determination of sinus node response to overdrive suppression-that is, sinus node recovery time. Most related studies have either differentiated between pathological and normal findings ${ }^{1-3}$ or examined methodological problems. ${ }^{4-6}$ Little information, however, is available on whether determination of sinus node recovery time is significantly influenced by haemodynamic changes occurring during rapid atrial pacing..$^{7-9}$ Several investigators found a pronounced fall in arterial blood pressure after a pacemaker induced increase in heart rate. ${ }^{10-12}$ Such a fall in arterial blood pressure activates arterial baroreceptors, which in turn increase sympathetic activity, suppress vagal inhibition, and affect both cardiac automaticity and sinus node recovery time. Our study investigated the effect of stimulation induced haemodynamic changes on the relation between sinus node recovery time and pacing rate.

Requests for reprints to Dr Reinhard Griebenow, Medizinische Klinik, Lehrstuhl II für Innere Medizin, Ostmerheimer Strasse 200, 5000 Köln 91, Federal Republic of Germany.

Accepted for publication 14 March 1984

\section{Patients and methods}

Thirty-one patients with a history of syncope or dizziness (17 men, 14 women; mean age 66.7 years) were examined. Sick sinus syndrome (that is, spontaneous episodes of sinoatrial block or symptomatic sinus bradycardia with sinus node recovery time exceeding $1500 \mathrm{~ms}$ or corrected sinus node recovery time exceeding $500 \mathrm{~ms}$ ) was established in 11 of these patients and hypersensitive carotid sinus syndrome (asystole of $\geqslant 3$ $\mathbf{s}$ with dizziness or syncope during carotid sinus pressure) in nine. Electrophysiological tests showed no signs of sinoatrial dysfunction in the remaining 11 patients. At the time of the study 10 patients were taking long term medication with digitalis preparations, and three were receiving oral doses of ajmaline (40-80 mg/day) to control ventricular extrasystoles.

\section{PACING TECHNIQUE}

After informed consent had been obtained the patients were examined in the fasting state without sedation. Under local anaesthesia a hexapolar pacing wire (No 6F Elecath, Schlag, Berg-Gladbach, FRG) was introduced percutaneously through the right femoral vein and advanced into the region of the bun- 


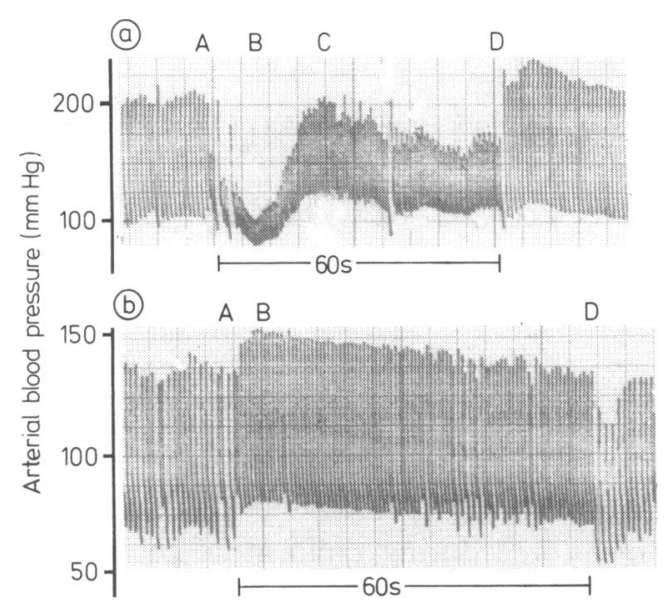

Figure Continuous blood pressure recording (femoral artery, 1 $\mathrm{mm} / \mathrm{s}$ ) of a 65 year old woman during rapid atrial pacing for the determination of sinus node recovery time $(a)$ at 130 beats/min and (b) at 85 beats/min. (a) At the beginning of atrial pacing a sharp fall $(B)$ in arterial blood pressure was followed by counter-regulatory rise $(C)$, during which systolic blood pressure returned to basal values. Thereafter blood pressure fell steadily until the end of the stimulation period $(D)$. Note three isolated periods of second degree atrioventricular block. (b) This blood pressure response seen at all pacing rates in almost all the patients in groups $1 b$ and 2 consisted of an initial rise in blood pressure with atrial pacing $(B)$ followed by a steady fall until the end of stimulation period (D). Note $C$ could not be measured. $A$, before pacing; $B$ and $C$, maximal change during pacing; $D$, end of stimulation period.

dle of His. A bipolar pacing wire was then introduced through the vein and positioned in the high right atrium. The intracardiac electrogram as well as responses from electrocardiogram surface leads I, II, and III were recorded on a six channel pen recorder (Cardirex 62, Siemens, Erlangen, FRG) with a paper speed of $100 \mathrm{~mm} / \mathrm{s}$. Overdrive pacing was carried out with a programmable stimulator (USM 30, Biomedix, Lörrach, FRG) for one minute followed by a one minute recovery period; the initial pacing rate of 70 beats/min was increased by 15 beats/min at each successive stimulation period. The maximum pacing rate was related to age ( 200 beats/min minus the age of the patient in years). One to one atrioventricular conduction was maintained during all stimulation periods, except for isolated periods of second degree atrioventricular block, which are of minor importance (Figure).

\section{MEASUREMENTS}

Sinus node recovery time was defined as the interval between the last paced $P$ wave and the first spontaneous atrial depolarisation, usually the first postpacing cycle. When one of the initial five postpacing cycles was longer than the first cycle (secondary pause) sinus node recovery time was based on the longer cycle. Corrected sinus node recovery time was defined as sinus node recovery time minus the mean duration of eight spontaneous prepacing cycles. Arterial blood pressure was monitored from the right femoral artery using a fluid filled polyethylene catheter (Seldicath, Intra, Saarbrücken, FRG) connected to a recording unit (Programme 19, Hellige, Freiburg, FRG) with a paper speed of $1 \mathrm{~mm} / \mathrm{s}$. Systolic and diastolic arterial blood pressures were measured to the nearest $5 \mathrm{~mm}$ $\mathrm{Hg}$ before pacing $(\mathrm{A})$, at the points of maximal change during pacing ( $B$ and $C$ ), and at the end of the stimulation period (D) (Figure $a$ and $b$ ).

\section{PATIENT GROUPS}

Those patients with a normal or slightly prolonged sinus node recovery time were assigned to group 1; those patients with an appreciably prolonged sinus node recovery time to group 2. For all patients in group 1 maximal sinus node recovery time was $\leqslant 2000$ ms and maximal corrected sinus node recovery time $\leqslant 750 \mathrm{~ms}$.

Group 1-Group 1 was further divided into two subgroups. Those patients with an initial fall in blood pressure during atrial pacing for at least one pacing rate were assigned to group la (11 men, 10 women; four with sick sinus syndrome, six with hyperactive carotid sinus syndrome, 11 with no detectable dysfunction). This initial fall in blood pressure was also seen at all subsequent (that is, higher) pacing rates. Those patients with no fall in blood pressure during pacing at any of the investigated pacing rates were assigned to group $1 \mathrm{~b}$ (five men, one woman; three with sick sinus syndrome, three with hyperactive carotid sinus syndrome).

Group 2-Those patients with a maximal sinus node recovery time $>2000 \mathrm{~ms}$ and a maximal corrected sinus node recovery time $>750 \mathrm{~ms}$ were assigned to group 2 (two men, two women; four with sick sinus syndrome); a pacing induced fall in blood pressure was not evident in any of these patients.

\section{Results}

The mean sinus node recovery time for all patients in groups $1 \mathrm{a}, 1 \mathrm{~b}$, and 2 increased steadily after stimulation at successively higher pacing rates up to 115 beats/min (Table 1). Sinus node recovery time decreased slightly at 130 beats/min and fell sharply at rates of 145 beats/min and higher (Table 1). Further analysis of the data showed a correlation between the pacing rate after which sinus node recovery time no longer increased and the fall in blood pressure during atrial pacing. Such a fall was seen for at least one 
Table 1 Mean $(S D)$ values for sinus node recovery time (SNRT) and corrected sinus node recovery time (CSNRT) in relation to pacing rate for all patients

\begin{tabular}{llllllll}
\hline \multicolumn{10}{l}{ Pacing rate (beats/min) } \\
\cline { 2 - 8 } & 70 & 85 & 100 & 115 & 130 & 145 & 160 \\
\hline SNRT (ms) & $1330(423)$ & $1370(747)$ & $1412(778)$ & $1423(1175)$ & $1380(1332)$ & $1063(335)$ & $843(258)$ \\
CSNRT (ms) & $413(397)$ & $417(762)$ & $477(789)$ & $467(1188)$ & $420(1409)$ & $188(316)$ & $118(166)$ \\
\hline
\end{tabular}

Table 2 Mean $(S D)$ values for systolic $(S)$ and diastolic $(D)$ blood pressure before pacing, at the point of maximal change (B and C), and after atrial pacing in three groups of patients

\begin{tabular}{|c|c|c|c|c|c|c|c|c|c|c|c|}
\hline \multirow{3}{*}{$\begin{array}{l}\text { Pacing } \\
\text { rates (beats/min) }\end{array}$} & \multirow[b]{3}{*}{$n$} & \multicolumn{2}{|c|}{ Before pacing (A) } & \multicolumn{4}{|c|}{ During pacing } & \multicolumn{2}{|c|}{ At end of pacing $(D)$} & \multirow[t]{3}{*}{ SNRT } & \multirow[t]{3}{*}{ CSNRT } \\
\hline & & \multirow[b]{2}{*}{$S$} & \multirow[b]{2}{*}{$D$} & \multicolumn{2}{|l|}{ Point B } & \multicolumn{2}{|l|}{ Point C } & \multirow[b]{2}{*}{$S$} & \multirow[b]{2}{*}{$D$} & & \\
\hline & & & & $s$ & $D$ & $S$ & $D$ & & & & \\
\hline $\begin{array}{l}70 \\
\text { Group 1a } \\
\text { Group 1b } \\
\text { Group 2 } \\
85\end{array}$ & $\begin{array}{r}14 \\
4 \\
3\end{array}$ & $\begin{array}{l}147(19) \\
152(31) \\
148(20)\end{array}$ & $\begin{array}{l}78(11) \\
80(16) \\
71(4)\end{array}$ & $\begin{array}{l}164(15) \\
158(33) \\
167(28)\end{array}$ & $\begin{array}{l}81(12) \\
79(12) \\
78(21)\end{array}$ & $\begin{array}{l}141(11) \\
-\end{array}$ & $\begin{array}{l}79(6) \\
-\end{array}$ & $\begin{array}{l}144(14) \\
160(36) \\
142(24)\end{array}$ & $\begin{array}{l}79(8) \\
84(12) \\
72(19)\end{array}$ & $\begin{array}{l}1339(148) \\
1255(59) \\
1926(240)\end{array}$ & $\begin{array}{l}338(167) \\
280(71) \\
722(146)\end{array}$ \\
\hline $\begin{array}{l}\text { Group la } \\
\text { Group 1b } \\
\text { Group } 2 \\
100\end{array}$ & $\begin{array}{r}19 \\
5 \\
4\end{array}$ & $\begin{array}{l}158(28) \\
156(35) \\
150(14)\end{array}$ & $\begin{array}{l}83(12) \\
82(14) \\
73(14)\end{array}$ & $\begin{array}{l}165(25) \\
163(33) \\
164(14)\end{array}$ & $\begin{array}{l}92(9) \\
91(15) \\
81(21)\end{array}$ & $\begin{array}{l}151(24) \\
-\end{array}$ & $\begin{array}{l}91(12) \\
-\end{array}$ & $\begin{array}{l}158(26) \\
155(31) \\
136(16)\end{array}$ & $\begin{array}{l}89(10) \\
86(13) \\
71(14)\end{array}$ & $\begin{array}{l}1233(134) \\
1318(226) \\
1908(762)\end{array}$ & $\begin{array}{l}306(93) \\
331(89) \\
926(931)\end{array}$ \\
\hline $\begin{array}{l}\text { Group 1a } \\
\text { Group 1b } \\
\text { Group } 2 \\
115\end{array}$ & $\begin{array}{r}29 \\
6 \\
4\end{array}$ & $\begin{array}{l}157(27) \\
152(31) \\
151(21)\end{array}$ & $\begin{array}{l}83(12) \\
81(12) \\
71(16)\end{array}$ & $\begin{array}{l}164(22) \\
156(32) \\
170(21)\end{array}$ & $\begin{array}{l}98(16) \\
93(16) \\
87(23)\end{array}$ & $\begin{array}{l}147(33) \\
-\end{array}$ & $\begin{array}{l}90(14) \\
-\end{array}$ & $\begin{array}{l}155(21) \\
141(29) \\
130(11)\end{array}$ & $\begin{array}{l}92(9) \\
83(19) \\
77(12)\end{array}$ & $\begin{array}{l}1223(196) \\
1250(255) \\
2657(1753)\end{array}$ & $\begin{array}{c}297(160) \\
295(146) \\
1538(1919)\end{array}$ \\
\hline $\begin{array}{l}\text { Group 1a } \\
\text { Group 1b } \\
\text { Group } 2 \\
130\end{array}$ & $\begin{array}{r}29 \\
6 \\
4\end{array}$ & $\begin{array}{l}158(28) \\
152(34) \\
151(18)\end{array}$ & $\begin{array}{l}83(12) \\
79(15) \\
67(7)\end{array}$ & $\begin{array}{l}157(23) \\
158(35) \\
170(23)\end{array}$ & $\begin{array}{r}100(11) \\
97(20) \\
85(24)\end{array}$ & $\begin{array}{l}148(32) \\
-\end{array}$ & $\begin{array}{l}90(14) \\
-\end{array}$ & $\begin{array}{l}154(22) \\
140(35) \\
138(11)\end{array}$ & $\begin{array}{l}96(11) \\
85(18) \\
78(19)\end{array}$ & $\begin{array}{l}1156(184) \\
1225(218) \\
2568(1838)\end{array}$ & $\begin{array}{c}233(142) \\
280(74) \\
1368(2063)\end{array}$ \\
\hline $\begin{array}{l}\text { Group 1a } \\
\text { Group 1b } \\
\text { Group } 2 \\
145\end{array}$ & $\begin{array}{r}17 \\
5 \\
4\end{array}$ & $\begin{array}{l}157(26) \\
153(35) \\
160(20)\end{array}$ & $\begin{array}{l}83(12) \\
80(14) \\
75(13)\end{array}$ & $\begin{array}{l}133(24) \\
152(32) \\
168(16)\end{array}$ & $\begin{array}{l}91(12) \\
97(22) \\
81(25)\end{array}$ & $\begin{array}{l}156(29) \\
125(22) \\
-\end{array}$ & $\begin{array}{l}103(16) \\
79(6) \\
-\end{array}$ & $\begin{array}{l}146(23) \\
141(32) \\
136(20)\end{array}$ & $\begin{array}{l}95(11) \\
90(18) \\
79(21)\end{array}$ & $\begin{array}{l}1102(242) \\
1260(163) \\
2793(2812)\end{array}$ & $\begin{array}{r}218(176) \\
310(129) \\
2157(3432)\end{array}$ \\
\hline Group la & 8 & $143(13)$ & $80(9)$ & $123(19)$ & $85(9)$ & $153(12)$ & $96(14)$ & $138(11)$ & $92(11)$ & $1063(335)$ & $188(316)$ \\
\hline Group la & 3 & $142(25)$ & $86(2)$ & $100(4)$ & $81(9)$ & $127(2)$ & $97(2)$ & $120(2)$ & $90(10)$ & $843(258)$ & $118(166)$ \\
\hline
\end{tabular}

pacing rate in $68 \%$ of all patients studied (group 1a).

The Figure shows a typical example of such a blood pressure response. During atrial pacing an initial rapid fall in blood pressure (B) was followed by a phase in which pressure returned to the basal value (recovery period) (C) and then dropped steadily until the end of the stimulation period (D). Mean blood pressures before pacing (A), at the points of maximal change ( $B$ and $C$ ), and at the end of the stimulation period (D) as well as the relation between sinus node recovery time and pacing rate for the patients in group la are shown in Table 2 . In this group mean systolic blood pressure during atrial pacing at rates up to 100 beats/min rose initially at $B$ and then at rates higher than 130 beats/min fell at $B$.

Pacing rates precipitating an initial fall in arterial blood pressure varied considerably from patient to patient (range $85-160$ beats $/ \mathrm{min}$ ). Nevertheless, 18 of 21 patients showed an initial fall in blood pressure during atrial pacing at rates of $\leqslant 130$ beats/min. Mean systolic blood pressure did not rise initially, and mean sinus node recovery time and mean corrected sinus node recovery time fell slightly during pacing at 115 beats/min. This fall was considerably more pronounced at higher pacing rates (Table 2).

The sinus node recovery time and corrected sinus node recovery time values for each patient in group la were divided into those obtained at pacing rates inducing an initial fall in blood pressure and those obtained at rates without an initial fall. The maximal sinus node recovery time and corrected sinus node recovery time values for each patient in these two subgroups were then selected. Using the Wilcoxon test, the mean maximal sinus node recovery time and mean maximal corrected sinus node recovery time for stimulation periods without a fall in blood pressure for group la as a whole were then compared with values for stimulation periods with an initial fall in blood pressure. The maximal sinus node recovery time without a fall in blood pressure during pacing (mean $1257 \mathrm{~ms}$ ) was significantly longer than that with a fall (1102 ms $\mathrm{p}<0.01)$. The mean corrected 
sinus node recovery time for stimulation periods without an initial fall in blood pressure was $307 \mathrm{~ms}$ compared with $227 \mathrm{~ms}$ for those periods with an initial decline ( $p<0.01$, Wilcoxon test).

An initial pacing induced fall in blood pressure was not detectable at rates under 130 beats $/ \mathrm{min}$ in six patients in group $1 \mathrm{~b}$ (Table 2). During stimulation blood pressure either remained constant initially or rose slightly and then dropped to the basal value or slightly below by the end of the stimulation period (for a typical response see the Figure). In addition, no relation could be established between maximal sinus node recovery time and corrected sinus node recovery time or blood pressure during atrial pacing for any patient in group $1 \mathrm{~b}$. The blood pressure changes during atrial pacing in the four patients in group 2 with prolonged sinus node recovery time closely resembled those in group $1 \mathrm{~b}$. No correlation existed between maximal sinus node recovery time and maximal corrected sinus node recovery time or blood pressure changes during atrial pacing for these patients (Table 2).

\section{Discussion}

Other investigators have shown a decrease in the sinus node recovery time at pacing rates of 120 to 150 beats/min or even higher. ${ }^{13-15}$ The mean sinus node recovery time pattern in our study was similar (Table 1). Two factors known to influence sinus node automaticity and response to overdrive pacing are changes in autonomic tone ${ }^{16}$ and pacing induced local mechanisms (for example, release of neurotransmitters or changes in ion concentrations)..$^{17-19}$

Our study was designed to determine whether the pacing induced fall in arterial blood pressure that is presumed to occur at high pacing rates due to reflex mediated alterations in sinus node automaticity influences sinus node recovery time. An initial fall in blood pressure during atrial pacing for at least one pacing rate was detected in $68 \%$ of our patients (Table 2). This finding also agrees with those of other studies of initial blood pressure response during the onset of paroxysmal supraventricular tachycardia or rapid atrial pacing. ${ }^{10-12}$ Such a decrease in blood pressure sustained for several cardiac cycles results in rapid sympathetic activation, ${ }^{20} 21$ which then produces a counter-regulatory rise in blood pressure and a concomitant increase in heart rate. ${ }^{22} 23$ The magnitude of the counter-regulatory rise and the increase in heart rate depend on the baroreflex sensitivity, which varies in relation to the patient's age and basal blood pressure. ${ }^{24} 25$

Studies of the characterisation of the human heart rate response to a temporary fall in arterial blood pressure have shown that the heart rate increase adapts very little during prolonged reduction of transmural pressure in the region of the carotid sinus.22 23 This finding was confirmed by Curry, who showed that the reduction in the atrioventricular conduction time occurring with a fall in arterial pressure during induced supraventricular tachycardia persists even after blood pressure has returned to the basal value. ${ }^{10}$

Several mechanisms, however, are known to influence this baroreflex mediated counter-regulatory rise in blood pressure during a fall in arterial blood pressure. An increase in pressure amplitude, such as we regularly observed during the counter-regulatory rise in blood pressure (Table 2), elicits a depressor response. 26-28 $^{-28}$ This depressor response in turn attenuates a pressor response, which is simultaneously modulated by concomitant beta adrenergic and cholinergic mechanisms. ${ }^{29}$

Although the pacing rate at which a certain blood pressure amplitude influences the carotid sinus may also be responsible for the pronounced fall in arterial blood pressure after an initial rise, at rates between 70 and 100 beats $/ \mathrm{min}$, it probably plays a minor role at higher rates. ${ }^{262830}$ All catheterisations were performed between 0800 and 1200 hours to eliminate any effect of circadian variations in baroreflex sensitivity. ${ }^{31}$ In summary, an initial fall in arterial blood pressure, such as occurs during rapid atrial pacing for determination of sinus node recovery time, elicits a baroreflex response with a compensatory rise in blood pressure and increase in sinus node automaticity. This increase probably persists for the entire one minute stimulation period, thus preventing further prolongation of sinus node recovery time at higher pacing rates.

Given these experimental findings, however, it is also highly improbable that changes in sinus node recovery time can be quantitatively predicted in the individual patient on the basis of blood pressure changes during atrial pacing. Our findings support these assumptions. In 21 of our $31(68 \%)$ patients a stimulation induced initial fall in arterial blood pressure was evident during at least one stimulation period. Pacing rates that initially induced this fall varied from 85 to 160 beats/min depending on the patient. This variation was probably due to differences in the functional status of the heart.

Classification of individual sinus node recovery times according to those obtained in stimulation runs with an initial fall in arterial blood pressure and those at pacing rates without a fall showed that the mean $\stackrel{\infty}{?}$ maximal values for the group with an initial fall were $\square$ significantly lower than those for the group without a 0 . fall. Although a more pronounced suppression of $\stackrel{\Phi}{\Omega}$ sinus node automaticity, such as is reflected by a pro- $\mathbb{D}$ longation of sinus node recovery time, is to be expected at higher pacing rates, this is not the case 
when a pacing induced decline in blood pressure occurs. No correlation could be established between the magnitude of changes in blood pressure and the magnitude of changes in sinus node recovery time.

In contrast to our findings Mandel et al were unable to show a relation between changes in arterial blood pressure during atrial pacing and maximal sinus node recovery time, but they did establish that sinus node recovery time after ventricular pacing with $1: 1$ retrograde ventriculoatrial conduction was always shorter than after atrial pacing. ${ }^{14}$ This supports our findings in so far as cardiac output during ventricular pacing is appreciably lower than during atrial pacing at the same rate. ${ }^{1232}$ This decrease in cardiac output with the subsequent changes in arterial blood pressure may also elicit baroreflex mediated sympathetic activation, as Paulay and Damato found in the $\operatorname{dog} .^{8}$ Mason also established an "organised relationship" between sinus node recovery time and pacing rate in most patients with denervated (transplanted) hearts and an irregular pattern in the control group. ${ }^{7}$

In contrast to the patients in group 1, none of the pacing rates used to determine sinus node recovery time induced a fall in arterial blood pressure in patients in groups $1 \mathrm{~b}$ and 2 . In these patients the response to atrial pacing was an initial rise in blood pressure followed by a steady fall until the end of the stimulation period (Figure b). This initial rise in blood pressure was only occasionally followed by a pronounced fall and a slight rise to the basal values toward the end of the stimulation period.

No relation between maximal sinus node recovery time and blood pressure response with different atrial pacing rates could be established for these patients. Interestingly enough the biphasic blood pressure response described above was detected in all four patients with appreciably prolonged sinus node recovery time (group 2). It may be that baroreflex mediated alterations in sinus node automaticity are responsible for sick sinus syndrome in these patients. This would then reflect abnormally high vagal tone instead of intrinsic impairment of sinus node function, both of which can cause sick sinus syndrome. ${ }^{16}$ The total autonomic blockade necessary for reliable differentiation between these two causes of sick sinus syndrome was not, however, performed.

In conclusion, invasive determination of sinus node recovery time is advisable in patients with sick sinus syndrome when non-invasive methods fail to provide sufficient information. Prolonged sinus node recovery time is a specific, but a less sensitive, indicator of sick sinus syndrome, ${ }^{33}$ probably because the absolute values for sinus node recovery time are the net result of a complex interplay of pacing rate, atriosinus conduction, autonomic tone at the time of pacing, and local mechanisms induced by pacing.
Our study showed that a temporary fall in arterial blood pressure induced by atrial stimulation at high pacing rates increases sinus node automaticity probably owing to baroreflex-mediated sympathetic activation. Additionally, this pacing induced decrease in arterial blood pressure represents an alternative to the theory that a decrease in sinus node recovery time after pacing at rates of 120 to 150 beats/min or higher is due to initiation of retrograde atriosinus blocking. ${ }^{34}$ For maximal suppression of sinus node activity, therefore, pacing rates should be used to determine sinus node recovery time that do not induce an initial fall in blood pressure-that is, pacing rates of 20 to 40 beats/min higher than the basal heart rate.

\section{References}

1 Breithardt G, Seipel L, Loogen F. Sinus node recovery time and calculated sinoatrial conduction time in normal subjects and patients with sinus node dysfunction. Circulation 1977; 56: 45-50.

2 Dhingra RC, Rosen KM, Rahimtoola SH. Normal conduction intervals and responses in sixty-one patients using His-bundle recording and atrial pacing. Chest 1973; 64: 55-9.

3 Narula OS, Samet P, Javier RP. Significance of the sinus-node-recovery time. Circulation 1972; 45: 140-58.

4 Chadda KD, Banka VS, Bodenheimer MM, Helfant RH. Corrected sinus node recovery time. Circulation 1975; 51: 797-801.

5 Jewell GM, Magorien RD, Schaal SF, Leier CV. Autonomic tone of patients during an electro-physiological catheterization. Am Heart f 1980; 99: 51-7.

6 Thormann J, Schlepper M. Zur Reproduzierbarkeit der Sinuskustenerholungszeit in Abhängigkeit von Tageszeit und 'overdrive'-Testfrequenz. $Z$ Kardiol 1980; 69: 542-50.

7 Mason JW. Overdrive suppression in the transplanted heart: effect of the autonomic nervous system on human sinus node recovery. Circulation 1980; 62: 688-96.

8 Paulay KL, Damato AN. Comparison of atrial and ventricular drive on sinus nodal function in the dog. Am 7 Cardiol 1973; 31: 41-6.

9 Pliam MB, Krellenstein DJ, Vassalle M, Brooks CMcC. Influence of the sympathetic system on the pacemaker suppression which follows overdrive. Circulation 1973; 48: 313-21.

10 Curry PVL. The hemodynamic and electrophysiological effects of paroxysmal tachycardia. In: Narula OS, ed. Cardiac arrhythmias. Baltimore: Williams and Wilkins, 1979: 364-81.

11 Goldreyer BN, Kastor JA, Kershbaum KL. The hemodynamic effects of induced supraventricular tachycardia in man. Circulation 1976; 54: 783-9.

12 Nakano J. Effects of atrial and ventricular tachycardias on the cardiovascular dynamics. Am $\mathcal{F}$ Physiol 1964; 206: 547-52.

13 Kulbertus HE, de Leval-Rutten F, Mary L, Casters P. 
Sinus node recovery time in the elderly. Br Heart $\mathcal{F}$ 1975; 37: 420-5.

14 Mandel WJ, Hayakawa H, Danzig R, Marcus HS. Evaluation of sinoatrial node function in man by overdrive suppression. Circulation 1971; 44: 59-66.

15 Mandel WJ, Hayakawa H, Allen HN, Danzig R, Kermaier AJ. Assessment of sinus node function in patients with the sick sinus syndrome. Circulation 1972; 46: 7619.

16 Jordan JL, Yamaguchi I, Mandel WJ. Studies on the mechanism of sinus node dysfunction in the sick sinus syndrome. Circulation 1978; 57: 217-23.

$17 \mathrm{Lu} \mathrm{HH}$, Lange G, Brooks ChMcC. Factors controlling pacemaker action in cells of the sinoatrial node. Circ Res 1965; 17: 460-71.

18 Vassalle $M$. The relationship among cardiac pacemakers. Circ Res 1977; 41: 269-77.

19 Vincenzi FF, West TC. Release of autonomic mediators in cardiac tissue by direct subthreshold electrical stimulation. F Pharmacol Exp Ther 1963; 141: 185-94.

20 Pickering TG, Gribbin B, Sleight P. Comparison of the reflex heart rate response to rising and falling arterial pressure in man. Cardiovasc Res 1972; 6: 277-83.

21 Sundlöf G, Wallin BG. Human muscle nerve sympathetic activity at rest. Relationship to blood pressure and age. f Physiol (Lond) 1978; 274: 621-37.

22 Bjurstedt H. Rosenhamer G, Tyden G. Cardiovascular responses to changes in carotid sinus transmural pressure in man. Acta Physiol Scand 1975; 94: 497-505.

23 Thron HL, Brechmann W, Wagner J, Keller K. Quantitative Untersuchungen über die Bedeutung der Gefäßdehnungsreceptoren im Rahmen der Kreislaufhomoiostase beim wachen Menschen. Pfunegers Arch 1967; 293: 68-99.

24 Bristow JD, Honour AJ, Pickering GW, Sleight P, Smyth HS. Diminished baroreflex sensitivity in high blood pressure. Circulation 1969; 39: 48-54.

25 Gribbin B, Pickering TG, Sleight P, Peto R. Effect of age and high blood pressure on baroreflex sensitivity in man. Circ Res 1971; 29: 424-31.

26 Angell James JE, de Burgh Daly M. Comparison of the reflex vasomotor responses to separate and combined stimulation of the carotid sinus and aortic arch baroreceptors by pulsatile and non-pulsatile pressures in the dog. F Physiol (Lond) 1970; 209: 257-93.

27 Angell James JE, de Burgh Daly M. Effects of graded pulsatile pressure on the reflex vasomotor responses elicited by changes of mean pressure in the perfused carotid sinus-aortic arch regions of the dog. $\mathcal{F}$ Physiol (Lond) 1971; 214: 51-64.

28 Angell James JE. The effects of altering mean pressure, pulse pressure and pulse frequency on the impulse activity in baroreceptor fibres from the aortic arch and right subclavian artery in the rabbit. I Physiol (Lond) 1971; 214: 65-88.

29 Evans JM, Knapp CF, Lowery TR. Pressor response buffering by $B$-adrenergic and cholinergic vasodilation in tranquilized dogs. Am $\mathcal{F}$ Physiol 1979; 236: H 165-73.

30 Stegemann J, Tibes U. Der EinfluB von Amplitude, Frequenz und Mittelwert sinusförmiger Reizdrucke an den Pressoreceptoren auf den arteriellen Mitteldruck des Hundes. Pfunegers Arch 1969; 305: 219-28.

31 Hossmann V, Fitzgerald GA Dollery CT. Circadian rhythm of baroreflex reactivity and adrenergic vascular response. Cardiovasc Res 1980; 14: 125-9.

32 Saborowski F, Hossmann V, Griebenow R, Sy M, Dundalek E, Engelhardt GH. Hemodynamic results of atrial and ventricular stimulation at different heart rates in patients with sick sinus syndrome [Abstract]. PACE 1981; 4: 70.

33 Breithardt G, Seipel L, Wiebringhaus E, Leuner Ch. Diagnostische Wertigkeit verschiedener Parameter der Sinusknotenfunktion. Z Kardiol 1979; 68: 382-9.

34 Kerr CR, Strauss HC. Effect of atrial pacing on atriosinus conduction [Abstract]. Circulation 1980; 62 (suppl 3): 174. 